\title{
ANTECEDENTS OF ONLINE PURCHASING BEHAVIOR ANTESENDEN PERILAKU PEMBELIAN SECARADARING
}

\author{
Rini Kuswati dan Amalia Saleha \\ Universitas Muhammadiyah Surakarta Jl. A. Yani Tromol Pos 1 Pabelan, Surakarta, Indonesia \\ Email: rk108@ums.ac.id, amaliasaleha15@gmail.com
}

\begin{abstract}
-
This study aims to determine the effect of information quality, service quality, as antecedent of online purchasing decision behavior. The population in this study is consumer who had been shopping for products or goods through the sale and purchase site of tokopedia.com. This study using 100 respondents, sampling technique with purposive sampling method. The paradigm of this study is positivism and using survey as design research. Data analyzed in this research includes measurement test, normality test, multicollinearity test and heteroskedastisity test. Hypothesis testing using multiple linear regression analysis, $t$-test, $F$ test, and the value of coefficient of determination $\left(R^{2}\right)$. The results showed that the quality of information has a positive and significant effect on the behavior of online purchasing decisions. Service quality variable have positive and significant effect to online purchasing decision behavior. Confidence variables have a significant and negative effect on online purchase decision behavior. Simultaneously the quality of information, service quality, and trust have a significant influence on the behavior of purchasing decision. The variance of independent variables in explainable online decision are 17,4\% and the rest explained by other variable outside of this research.
\end{abstract}

Keywords: Quality of Information, Service Quality, Trust and Online Purchasing Behavior.

\begin{abstract}
Abstraksi-Penelitian ini bertujuan untuk mengetahui pengaruh kualitas informasi, kualitas layanan, sebagai anteseden perilaku keputusan pembelian online. Populasi dalam penelitian ini adalah konsumen yang telah berbelanja produk atau barang melalui situs jual beli tokopedia.com. Penelitian ini menggunakan 100 responden, teknik pengambilan sampel dengan metode purposive sampling. Paradigma penelitian ini adalah positivisme dan menggunakan survei sebagai penelitian desain. Analisis data dalam penelitian ini meliputi uji pengukuran, uji normalitas, uji multikolinearitas dan uji heteroskedastisitas. Pengujian hipotesis menggunakan analisis regresi linier berganda, t-test, uji F, dan nilai koefisien determinasi $\left(\mathrm{R}^{2}\right)$. Hasil penelitian menunjukkan bahwa kualitas informasi memiliki pengaruh positif dan signifikan terhadap perilaku keputusan pembelian online. Variabel kualitas layanan berpengaruh positif dan signifikan terhadap perilaku keputusan pembelian online. Variabel keyakinan memiliki pengaruh yang signifikan dan negatif terhadap perilaku keputusan pembelian online. Bersamaan dengan itu kualitas informasi, kualitas layanan, dan kepercayaan memiliki pengaruh yang signifikan terhadap perilaku keputusan pembelian. Varians variabel independen dalam keputusan online yang dapat dijelaskan adalah $17,4 \%$ dan sisanya dijelaskan oleh variabel lain di luar penelitian ini.
\end{abstract}

Kata Kunci: Kualitas Informasi, Kualitas Layanan, Kepercayaan, dan Perilaku Pembelian Online

\section{PENDAHULUAN}

Perkembangan teknologi informasi yang semakin pesat membawa beberapa perubahan dalam berbagai aspek kehidupan, salah satunya gaya hidup masyarakat yang menjadi serba praktis. Adanya internet mempermudah masyarakat dalam mencari informasi di era globalisasi seperti saat ini. Informasi bisa diperoleh dari seluruh penjuru dunia tanpa mengenal batas waktu dan geografis karena penggunanya terhubung melalui sistem komputer secara global. Internet mampu menggantikan peran dalam tatanan hidup masyarakat. Toko-toko konvensional kini telah tergantikan dengan hadirnya toko daring (online) yang menyediakan segala kebutuhan gaya hidup secara lebih lengkap (Sujana \& Suprapti, 2016).

Berbagai transaksi jual beli yang sebelumnya hanya bisa dilakukan dengan cara tatap muka (dan sebagian sangat kecil melalui pos atau telepon), kini sangat mudah dan sering dilakukan melalui internet (Widodo, Putranti, \& Nurchayati, 2016). Menurut Asosiasi Penyelenggara Jasa Internet Indonesia (APJII) mengungkapkan jumlah pengguna internet di Indonesia tahun ke tahun pengguna internet 
diperkirakan semakin lama akan semakin meningkat (Alwafi \& Magnadi, 2016).

Meskaran, Fatemeh, Zuraini Ismail, \& Bharani Shanmugam (2013), menjelaskan bahwa saat ini belanja daring adalah salah satu cara berbelanja yang sedang marak digunakan dalam transaksi jual beli. Toko daring juga merupakan bentuk jual beli melalui alat komunikasi elektronik atau jejaring sosial di mana pembeli tidak perlu susah payah datang ke toko untuk melihat dan membeli apa yang mereka cari karena dengan adanya belanja daring mereka hanya tinggal melihat barang yang diinginkan di internet kemudian memesan barang sesuai pilihan dan mentransfer uangnya lalu barang dikirim oleh toko daring dan sampai kerumah (Nusarika \& Purnami, 2015). Eka (2016), berpendapat bahwa era digital yang masuk ke Indonesia saat ini telah merubah perilaku masyarakat yang mulanya membeli pada toko luring (offline) beralih pada toko daring (online). Dampak adanya hal tersebut adalah toko daring saat ini berkembang pesat dengan menjual beragam produk (Wijayanti \& Harti, 2017). Perkembangan bisnis daring atau jual beli dengan menggunakan media internet yang biasa disebut toko daring (e-commerce) semakin marak dilakukan oleh banyak orang (Jayanti, 2015).

Dari latar belakang diatas, maka penulis mencoba untuk mengetahui variabel-variabel yang mempengaruhi perilaku keputusan pembelian secara daring dan tertarik untuk mengangkat judul “ Antecenden Perilaku Pembelian Secara Daring”.

\section{KAJIAN TEORI}

\section{Keputusan Pembelian Daring}

Menurut Deavaj, Fan, \& Kohli dalam Pratama (2015), keputusan pembelian dalam jaringan adalah proses pembelian yang dilakukan konsumen melalui proses alternatif dengan menggunakan media internet yang memiliki nilai manfaat yang lebih tinggi (Anggraeni \& Madiawati, 2016). Masih menurut Deavaj et al, (2003) dalam Pratama dan Nugrahani (2015), keputusan pembelian secara daring di pengaruhi oleh beberapa faktor, faktor pertama efisiensi untuk pencarian (waktu cepat, mudah dalam penggunaan, dan usaha dalam pencarian yang mudah), faktor kedua value (harga bersaing dan kualitas baik) dan faktor ketiga interaksi (informasi, keamanan, load time, dan navigasi).

Sedangkan menurut Katawetawaraks dan Wang; Uddin, Lopa, \& Oheduzzaman (2014), keptusan pembelian secara daring adalah tindakan konsumen dalam melakukan keputusan belanja daring. Adapun indikatornya yaitu: (1) Mantab atas keputusan. (2) Cepat dalam memutuskan. (3) Yakin keputusan tepat. Indikator keputusan pembelian secara daring menurut Schiffman and Kanuk (2008:485) yaitu (1) pilihan produk, (2) efisiensi pencarian, artinya waktu yang cepat untuk mengakses toko daring, (3) interaksi, yang meliputi keamanan dan navigasi, (4) waktu pembelian, dan (5) pilihan metode pembayaran.

\section{Kualitas Informasi}

Kualitas informasi ialah kualitas yang berkaitan dengan jumlah, akurasi dan bentuk informasi tentang produk dan jasa yang ditawarkan pada sebuah situs web (Nusair, Mohammed T, et al 2008 dalam Sam dan Tahir, 2009:5). Berdasarkan definisi tersebut kualitas informasi yang dimaksud adalah kualitas web yang terdiri dari isi website, kesesuaian dan bentuk informasi, jumlah, akurasi dan relevansi tentang produk atau jasa pada web yang ditunjukkan pada pengguna (Alhasanah, Kertahadi, \& Riyadi, 2014), Kualitas situs web menurut Barnes dan Vidgen (2001) terdiri dari; (1) kualitas informasi website; (2) kualitas tampilan website; (3) kualitas penggunaan, (Sujana \& Suprapti, 2016).

Menurut Burch dan Grudnitski dalam Sutabri (2012: 33), menjabarkan kualitas dari suatu informasi tergantung dari tiga hal yaitu: (1) Akurat (accuracy). (2) Tepat waktu (timeliness). (3) Relevan (relevancy) (Anggraeni \& Madiawati, 2016). Didalam berbelanja daring sebaiknya menyajikan informasi yang mencakup kaitannya dengan produk dan jasa yang ada pada daring shopping. Hal tersebut dapat membantu pembeli didalam membuat keputusan, konsisten dan mudah dipahami. Menurut Barnes (2005), kualitas informasi meliputi hal-hal seperti informasi yang akurat, informasi yang bisa di percaya, informasi yang up to date atau terbaru, informasi yang sesuai dengan topik bahasan, informasi yang mudah dimengerti, 
informasi yang sangat detail dan mendalam, dan informasi yang disajikan dalam format desain yang sesuai (Kuspriyono, 2017).

\section{Kualitas Pelayanan}

Lovelock dalam Tjiptono (2011: 58), mengemukakan bahwa kualitas pelayanan merupakan tingkatan kondisi baik buruknya sajian yang diberikan oleh penjual dalam rangka memuaskan konsumen dengan memberikan atau menyampaikan keinginan atau permintaan konsumen melebihi apa yang diharapkan konsumen (Raje, Archana dan Vandana T. K, 2012). Kualitas layanan dalam penjualan produk secara daring sangat diperlukan karena adanya hubungan tidak langsung antara pembeli dan penjual. Dalam e-commerce, kepercayaan konsumen menjadi prioritas, untuk itu dibutuhkan kemampuan yang cakap dalam melayani konsumen. Kualitas pelayanan dalam penjualan produk daring meliputi kejujuran, kecepatan menanggapi pertanyaan konsumen, pemberian jaminan/garansi, proses pengiriman, kerapian kemasan dan pelayanan lainnya yang mendukung dalam mendapatkan kepercayaan konsumen. Kesulitan dalam melakukan transaksi menjadi salah satu kendala konsumen melakukan pembelian produk secara daring (Setyarko, 2016). Pada penelitian yang dilakukan, diidentifikasikan 6 dimensi kualitas pelayanan daring, yaitu: (1) Kehandalan (reliability); (2) Ketanggapan (responsiveness); (3)Pengetahuan harga (price knowledge); (4) Fleksibilitas (flexibility); (5) Keamanan dan privasi (security and privacy); (6) Jaminan atau kepercayaan (assurancel trust) (Kuspriyono, 2017).

\section{Kepercayaan}

Menurut Schurr dan Ozanne (1985), mendefenisikan kepercayaan sebagai kepercayaan akan janji yang diberikan perusahaan dan usaha pemenuhan janji tersebut dalam melakukan hubungan dengan pelanggan. Kepercayaan mengacu pada keyakinan pelanggan bahwa janji yang diberikan perusahaan kepada pelanggan dapat dipercaya dan memberikan aksi yang salingmenguntungkan mengacu kepada perusahaan (Kuswati \& Delima, 2014). Menurut Hsiao, Lin, Wang, Lu, \& Yu (2010), dalam penelitiannya mendefinisikan kepercayaan terhadap situs belanja daring sebagai kesediaan konsumen dalam mempercayai situs belanja daring (Anwar \& Adidarma, 2016). Sedangkan menurut Morman (1993) kepercayaan sebagai kemauan untuk bergantung pada penjual yang dapat dipercaya. Jika konsumen percaya, mereka yakin bahwa perilakunya dalam berbelanja daring tidak menimbulkan masalah, dan bersikap positif serta mau berbelanja daring pada masa yang akan datang (Setiawan \& Fauziah, 2017). Menurut McKnight dan Chervany (2002), menjelaskan secara rinci komponen-komponen kepercayaan menjadi: (1) Integritas; (2) Benevolence (kebaikan hati); (3) Competency; (4) Predictability (Anwar \& Adidarma, 2016). Sedangkan menurut penelitian yang dilakukan Robbins dan Judge (2007), kepercayaan memiliki tiga dimensi, dimensi kepercyaan adalah: (1) Integritas: (2) Kompetensi: (3) Konsistensi: (Anggraeni \& Madiawati, 2016).

\section{METODE PENELITIAN}

\section{Populasi, Sample dan Metode Pengambilan Sampel}

Polulasi dalam studi ini tidak diketahui sampling framenya, sehingga peneliti mengambil sample secara non probability, dengan purposive sampling method. Metode purposive sampling yaitu teknik penentuan sampel dengan pertimbangan syarat atau kriteria tertentu. Kriteria pemilihan sampel di dalam penelitian ini yaitu responden yang pernah melakukan pembelian produk pada situs jual beli tokopedia.com, pendidikan minimal SMA sederajat dan sudah berumur 18 tahun dengan anggapan atau asumsi dapat memahami pertanyaan-pertanyaan dan mengisi atau menjawab kuesioner dengan baik. Jumlah sampel sebanyak 100 responden. Metode pengumpulan data yang digunakan dalam penelitian ini adalah menggunakan bentuk angket/kuesioner. Penyebaran kuesioner pada sampel telah ditentukan (konsumen yang pernah melakukan pembelian melalui situs jual beli tokopedia.com), kemudian peneliti memberikan kuesioner tersebut kepada responden untuk diisi dan menjawab pertanyaan-pertanyaan yang ada pada lembar kuesioner. 


\section{Definisi Operasional Variabel}

Tabel 1. Definisi Operasional Variabel

\begin{tabular}{|c|c|c|c|c|}
\hline No & Variabel & Definisi & Indikator & Sumber \\
\hline 1 & Dependen & & & \\
\hline & $\begin{array}{l}\text { Ke putus a n } \\
\text { pe m belia n } \\
\text { secara daring }\end{array}$ & $\begin{array}{l}\text { Menurut Deavaj et al, dalam Pratama } \\
\text { (2015), keputusan pembelian dalam } \\
\text { jaringan adalah proses pembelian yang } \\
\text { dilakukan konsumen melalui proses } \\
\text { alternatif dengan menggunakan media } \\
\text { internet yang memiliki nilai manfaat } \\
\text { yang lebih tinggi. Diukur dengan } 6 \\
\text { indikator. }\end{array}$ & $\begin{array}{l}\text { 1. Efisiensi untuk pencarian } \\
\text { 2. Interaksi yang meliputi } \\
\text { keamanan dan navigasi } \\
\text { 3. Waktu pembelian } \\
\text { 4. Pilihan metode pembayaran } \\
\text { 5. Pilihan produk } \\
\text { 6. Value (harga bersaing dan } \\
\text { kualitas baik). }\end{array}$ & $\begin{array}{l}\text { Deavaj et al., (2015) } \\
\text { Katawetawaraks \& } \\
\text { Wang; Uddin et al., } \\
(2014) \\
\begin{array}{l}\text { Schiffman \& Kanuk, } \\
(2008)\end{array}\end{array}$ \\
\hline
\end{tabular}

2 Independen

Park and kim, dalam Achyar dan Brilliant (2013), mendefinisikan $\mathrm{K}$ u a $1 \mathrm{i}$ t a s kualitas informasi sebagai persepsi Informasi a pelanggan terhadap kualitas informasi tentang produk atau layanan yang disediakan oleh sebuah website. Diukur dengan 9 indikator.

Lovelock dalam Tjiptono (2011: 58), mengemukakan bahwa kualitas pelayanan merupakan tingkatan kondisi baik buruknya sajian yang diberikan $\mathrm{K}$ u a $1 \mathrm{i}$ t a $\mathrm{s}$ oleh penjual dalam rangka memuaskan Pelayanan konsumen dengan memberikan atau menyampaikan keinginan atau permintaan konsumen melebihi apa yang diharapkan konsumen. Diukur dengan 6 indikator.

Morman (1993) kepercayaan sebagai kemauan untuk bergantung pada penjual yang dapat dipercaya. Jika konsumen percaya, mereka yakin Kepercayaan bahwa perilakunya dalam berbelanja daring tidak menimbulkan masalah, dan bersikap positif serta mau berbelanja daring pada masa yang akan datang. Diukur dengan 4 indikator.
1. Informasi akurat

2. Informasi tepat waktu

3. Informasi relevan

4. Informasi terpercaya

5. Informasi up to date (terbaru)

6. Informasi sesuai dengan topik atau tema

7. Informasi mudah dimengerti

8. Informasi detail atau lengkap

9. Format informasi yang disajikan menarik

1. Kehandalan

2. Ketanggapan

3. Pengetahuan harga Barnes \& Vidgen,

4. Fleksibilitas: pilihan dalam (2002) cara membayar, mengirimkan, Parasuraman et al., membeli, mencari dan (2005) mengembalikan item

5. Keamanan dan privasi

6. Jaminan atau kepercayaan

1. Integritas (kejujuran dan kemampuan untuk menepati janji)

2. Benevolence (kebaikan hati ) McKnight \& Chervany,

3. Kemampuan (Competency): (2002) menyediakan, melayani, sampai Robbins \& Judge, mengamankan transaksi dari $\begin{aligned} & \text { Robbin } \\ & \text { (2007) }\end{aligned}$ gangguan pihak lain

4. Predictability (konsitensi memberikan kepastian akan produk/barang yang dijual

\section{Metode Analisis Data}

Metode analisis data yang dilakukan dalam penelitian ini adalah dilakukan uji Analisis linear berganda ini digunakan untuk mengetahui ada tidaknya pengaruh variabel independen yaitu kualitas informasi, kualitas pelayanan, dan kepercayaan terhadap variabel dependen keputusan pembelian secara daring. Sebelum uji regresi dilakukan, peneliti melakukan uji normalitas dan bebrapa uji asumsi klasik terlebih dahulu. Adapun persamaan regresi dalam penelitian ini dapat disusun sebagai berikut:

$$
\mathrm{Y}=\mathrm{a}+\beta_{1} X_{1}+\beta_{2} X_{2}-\beta_{3} X_{3}+\mathrm{e}
$$

\section{Keterangan:}

$$
\begin{aligned}
& \mathrm{Y}=\text { Keputusan Pembelian Daring } \\
& \mathrm{a}=\text { Konstanta } \\
& \beta_{1}=\begin{array}{l}
\text { Koefisien regresi variabel kualitas } \\
\text { informasi }
\end{array} \\
& \beta_{2}=\begin{array}{l}
\text { Koefisien regresi variabel kualitas } \\
\text { pelayanan }
\end{array} \\
& \beta_{3}=\text { Koefisien regresivariabel kepercayaan }
\end{aligned}
$$


$X_{1}=$ Kualitas informasi

$X_{2}=$ Kualitas Pelayanan

$X_{3}=$ Kepercayaan

$\mathrm{e}=$ Error disturbances

\section{DISKUSI HASIL}

\section{Uji Validitas}

Hasil uji validitas dalam penelitian ini menggunakan uji analisis faktor konfirmatori (Confirmatory Factor Analisys = CFA). Butirbutir pertanyaan yang mempunyai faktor loading yang valid yaitu $\geq 0,50$.

\section{Tabel 2. Hasil Uji Validitas}

\begin{tabular}{|c|c|c|c|c|}
\hline & \multicolumn{4}{|c|}{ Component } \\
\hline & 1 & 2 & 3 & 4 \\
\hline Kinformasi_3 & & & ,797 & \\
\hline Kinformasi_7 & & & ,687 & \\
\hline Kinformasi_8 & & &, 783 & \\
\hline Kpelayanan_1 & & & &, 703 \\
\hline Kpelayanan_2 & & & &, 590 \\
\hline Kpelayanan_4 & & & & ,621 \\
\hline Kpelayanan_9 & & & &, 721 \\
\hline Kepercayaan_1 & & 670 & & \\
\hline Kepercayaan_2 & &, 785 & & \\
\hline Kepercayaan_3 & &, 506 & & \\
\hline Kepercayaan_4 & &, 658 & & \\
\hline Kepercayaan_5 & & ,684 & & \\
\hline Kepercayaan_6 & &, 637 & & \\
\hline Daring_2 & ,668 & & & \\
\hline Daring_3 &, 574 & & & \\
\hline Daring_4 &, 533 & & & \\
\hline Daring_5 & ,753 & & & \\
\hline Sumber: Data $p$ & er d & ah, 2 & & \\
\hline
\end{tabular}

Berdasarkan hasil uji CFA pada tabel diatas diketahui bahwa beberapa item telah mengelompok sesuai dengan indikatornya dan berdasarkan hasil diatas diketahui hanya beberapa item pernyataan yang dinyatakan valid dengan nilai loading faktor diatas 0,50 . Diketahui bahwa meskipun beberapa item telah mengelompok sesuai dengan indikatornya, akan tetapi berdasarkan hasil diatas diketahui bahwa tidak semua item pernyataan dinyatakan valid. Item Kinformasi_1, Kinformasi_2,
Kinformasi_4, Kinformasi_5, Kinformasi_6, Kinformasi_9, Kpelayanan_3, Kpelayanan_5, Kpelayanan_6, Kpelayanan_7, Kpelayanan_8, Kpelayanan_10, Kpelayanan_11, Daring_1, dan Daring_6 dinyatakan gugur karena memiliki nilai loading faktor dibawah 0,50.

\section{Uji Reliabilitas.}

Hasil pengujian reliabilitas untuk masingmasing variabel yang diringkas dalam tabel berikut:

Tabel 3. Hasil Uji Reliabilitas

\begin{tabular}{lcc}
\hline \multicolumn{1}{c}{ Variabel } & $\begin{array}{c}\text { Cronbach's } \\
\text { Alpha }\end{array}$ & Keterangan \\
\hline Kualitas Informasi & 0,503 & Tidak Reliabel \\
Kualitas Pelayanan & 0,601 & Reliabel \\
Kepercayaan & 0,799 & Reliabel \\
$\begin{array}{l}\text { Keputusan } \\
\text { Pembelian Daring }\end{array}$ & 0,749 & Reliabel \\
\hline \multicolumn{2}{c}{ Sumber: Data primer diolah, 2018 }
\end{tabular}

Hasil pengujian reliabilitas variabel kualitas pelayanan, kepercayaan, dan keputusan pembelian daring diperoleh nilai Cronbach's Alpha lebih besar dari kriteria yang ditentukan yaitu $>0,60$ yang mana menjelaskan bahwa ketiga variabel dianggap reliabel, sedangkan variabel kualitas informasi memiliki nilai Cronbach's Alpha sebesar 0,503 yang artinya kualitas informasi dianggap tidak reliabel.

\section{Uji Normalitas}

Pengujian normalitas menggunakan uji One-Sample Kolmogorov-Smirnov Test dengan SPSS 20.

Tabel 4. Hasil Uji Normalitas

\begin{tabular}{cc}
\hline & Undstandarized Residual \\
\hline $\mathrm{N}$ & 100 \\
Kolmogorov- &, 401 \\
Smirnov Z & \\
Asymp. Sig. &, 997 \\
(2-tailed) &
\end{tabular}


Hasil pengujian normalitas menunjukkan bahwa nilai Kolmogorov-Smirnov 0,401 dengan nilai signifikansi atau asymp. sig. (2-tailed) yang dihasilkan dari model penelitian ini adalah 0,997 > dari taraf signifikansi 0,05, maka dapat disimpulkan bahwa data dalam penelitian ini berdistribusi normal.

\section{Uji Multikolinearitas}

Pengujian multikolinearitas yaitu dengan melihat pada tolerance value dan varian inflation factor.

Tabel 5. Hasil Uji Multikolinearitas

\begin{tabular}{|c|c|c|c|}
\hline Variabel & Tolerance & VIF & Keterangan \\
\hline $\begin{array}{l}\text { Kualitas } \\
\text { Informasi }\end{array}$ & 1,000 & 1,000 & $\begin{array}{c}\text { Bebas } \\
\text { Multikolinearitas }\end{array}$ \\
\hline $\begin{array}{l}\text { Kualitas } \\
\text { Pelayanan }\end{array}$ & 990 & 1,010 & $\begin{array}{c}\text { Bebas } \\
\text { Multikolinearitas }\end{array}$ \\
\hline Kepercayaan & 990 & 1,010 & $\begin{array}{c}\text { Bebas } \\
\text { Multikolinearitas }\end{array}$ \\
\hline
\end{tabular}

Sumber: Data primer diolah, 2018
Dari hasil pengolahan data dalam tabel 4.13 menunjukkan hasil uji multikolinearitas. Ketiga variabel independen yaitu kualitas informasi, kualitas pelayanan, dan kepercayaan menunjukkan angka VIF kurang dari 10 dan nilai tolerance diatas 0,10 . Berdasarkan hasil tersebut dapat disimpulkan bahwa model regresi tersebut tidak terjadi masalah multikolinearitas, sehingga model regresi yang ada layak digunakan.

\section{Uji Heteroskedastisitas}

Pengujian heteroskedastisitas dalam penelitian adalah dengan melakukan uji korelasi Spearman yang dilakukan dengan mengkorelasikan variabel-variabel bebas terhadap nilai residual. Residual adalah selisih antara nilai variabel $X$ dengan nilai variabel $\mathrm{Y}$ yang diprediksi. Jika nilai signifikansi antara variabel independen dengan residual lebih dari 0,05 maka tidak terjadi masalah heteroskedastisitas.

Tabel 6. Hasil Uji Heteroskedastisitas

\begin{tabular}{|c|c|c|c|c|}
\hline & & & $\begin{array}{c}\text { Unstandarized } \\
\text { Residual }\end{array}$ & Keterangan \\
\hline \multirow{9}{*}{$\begin{array}{c}\text { Spearman's } \\
\text { rho }\end{array}$} & \multirow{3}{*}{ Kualitas informasi } & Correlation Coefficient &, 017 & \multirow{3}{*}{$\begin{array}{c}\text { Bebas } \\
\text { Heteroskedastisitas }\end{array}$} \\
\hline & & Sig. (2-tailed) &, 864 & \\
\hline & & $\mathrm{N}$ & 100 & \\
\hline & \multirow{3}{*}{ Kualitas pelayanan } & Correlation Coefficient &,- 043 & \multirow{3}{*}{$\begin{array}{c}\text { Bebas } \\
\text { Heteroskedastisitas }\end{array}$} \\
\hline & & Sig. (2-tailed) & 674 & \\
\hline & & $\mathrm{N}$ & 100 & \\
\hline & \multirow{3}{*}{ Kepercayaan } & Correlation Coefficient &,- 019 & \multirow{3}{*}{$\begin{array}{c}\text { Bebas } \\
\text { Heteroskedastisitas }\end{array}$} \\
\hline & & Sig. (2-tailed) &, 851 & \\
\hline & & $\mathrm{N}$ & 100 & \\
\hline
\end{tabular}

Sumber: Data primer diolah, 2018

Hasil uji heteroskedastisitas dapat sehingga dapat disimpulkan tidak terjadi diketahui bahwa ketiga variabel independen masalah heteroskedastisitas pada model memiliki nilai signifikansi lebih besar 0,05 regresi.

\section{Hasil Regresi Linear Berganda}

Tabel 7. Hasil Analisis Regresi

\begin{tabular}{ccccc}
\hline Model & B & Std. Error & t hitung & Sig \\
\hline (Constant) & 7,206 & 5,807 & 1,241 &, 218 \\
Kualitas Informasi &, 253 &, 084 & 3,002 &, 003 \\
Kualitas Pelayanan &, 232 &, 097 & 2,389 &, 019 \\
Kepercayaan &,- 188 &, 093 & $-2,022$ &, 046 \\
$\mathrm{R}^{2}$ & $=0,174$ & & & \\
Fhitung & $=6,753$ & & & \\
Ftabel & $=2,70$ & & & \\
ttabel & $=1,985$ & & & \\
\hline
\end{tabular}

Sumber: Data primer diolah, 2018 
Hasil persamaan regresi linier berganda sebagai berikut:

$\mathrm{Y}=7,206+0,253 X_{1}+0,232 X_{2}-0,188 X_{3}+\mathrm{e}$.

Persamaan regresi linier berganda mempunyai nilai konstanta sebesar 7,206 yang menunjukkan apabila variabel-variabel independen diasumsikan dalam keadaan tetap, maka variabel keputusan pembelian daring akan semakin menguat. Sementara dari hasil pengujian hipotesis dapat disimpulkan sebagai berikut:

\section{Uji Hipotesis pengaruh kualitas informasi terhadap keputusan pembelian daring.}

Berdasarkan hasil perhitungan untuk pengaruh kualitas informasi (X1) terhadap keputusan pembelian daring di peroleh nilai t hitung sebesar 3,002 dengan tingkat signifikansi 0,003 . Oleh karena nilai t hitung lebih besar dari t tabel $(3,002>1,985)$ dengan tingkat signifikansi $0,003<0,05$, maka Ho ditolak dan Ha diterima, yang berarti bahwa kualitas informasi berpengaruh signifikan terhadap keputusan pembelian daring. Disimpulkan bahwa secara parsial kualitas informasi berpengaruh positif signifikan terhadap keputusan pembelian daring.

\section{Uji Hipotesis pengaruh kualitas pelayanan terhadap keputusan pembelian daring.}

Berdasarkan hasil perhitungan untuk pengaruh kualitas pelayanan (X2) terhadap keputusan pembalian daring diperoleh nilai t hitung sebesar 2,389 dengan tingkat signifikansi 0,019 . Oleh karena nilai t hitung lebih besar dari nilai t tabel $(2,389>1,985)$ dengan tingkat signifikansi $0,019<0,05$, maka Ho ditolak dan $\mathrm{Ha}$ diterima, yang berarti bahwa kualitas pelayanan berpengaruh signifikan terhadap keputusan pembelian daring. Disimpulkan bahwa secara parsial kualitas pelayanan berpengaruh positif signifikan terhadap keputusan pembelian daring.

\section{Uji Hipotesis pengaruh kepercayaan terhadap keputusan pembelian daring.}

Berdasarkan hasil perhitungan untuk pengaruh kepercayaan (X3) terhadap keputusan pembelian daring diperoleh nilai $t$ hitung sebesar $-2,022$ dengan tingkat signifikansi 0,046 . Oleh karena nilai t hitung lebih besar dari t tabel $(-2,022>1,985)$ dengan signifikansi $0,046<0,05$, maka Ho ditolak dan Ha diterima, yang berarti bahwa kepercayaan berpengaruh signifikan terhadap keputusan pembelian daring. Disimpulkan bahwa secara parsial kepercayaan berpengaruh negatif signifikan terhadap keputusan pembelian daring. Pengaruh negatif ini bisa disebabkan kondisi sampel mahasiswa yang tidak menganggap penting memutuskan perilaku belanja online dari sisi kepercayaan konsumen pada situs tokopedia. Bahkan cenderung ingin mencoba situs lainnya ketika kepercayaan meningkat.

Berdasarkan hasil analisis uji $\mathrm{F}$ diperoleh nilai $F$ hitung sebesar 6,753 $>2,70$ dengan tingkat signifikansi sebesar $0,000<0,05$, hal ini berarti bahwa kualitas informasi, kualitas pelayanan, dan kepercayaan secara simultan berpengaruh terhadap keputusan pembelian daring. Sedangkan hasil perhitungan melalui program SPSS 20 dapat diketahui bahwa koefisien determinasi ( $R$ Square) diperoleh sebesar 0,174. Hasil ini berarti 17,4\% keputusan pembelian daring dapat dijelaskan melalui variabel kualitas informasi, kualitas pelayanan, dan kepercayaan sedangkan sisanya yaitu $82,6 \%$ dipengaruhi oleh variabel lain diluar dari penelitian ini.

\section{SIMPULAN}

Berdasarkan hasil penelitian secara parsial variabel kualitas informasi, kualitas pelayanan, dan kepercayaan memiliki pengaruh terhadap keputusan pembelian daring. Variabel kualitas informasi berpengaruh positif dan signifikan terhadap keputusan pembelian daring. Variabel kualitas pelayanan berpengaruh positif dan signifikan terhadap keputusan pembelian daring. Dengan demikian vendor penyedia layanan jual beli online sebaiknya meningkatkan kualitas pelayanan dan kualitas informasi kepada konsumen. Sementara variabel kepercayaan berpengaruh negatif dan signifikan terhadap keputusan pembelian daring. Hasil tersebut didukung oleh temuan Kuswati dan Delima (2014) yang menyatakan pula bahwa niat membeli secara daring tidak dipengaruhi oleh kuatnya kepercayaan konsumen pada situs online tertentu. Kondisi tersebut menggambarkan bahwa konsumen 
yang melakukan pembelian secara daring, tidak menempatkan kepercayaan sebagai prediktor positif dalam memutuskan pembelian. Prediktor positif perilaku pembelian secara daring sesuai hasil studi ini adalah kualitas informasi dan kualitas pelayanan dari situs online tersebut.

\section{DAFTAR PUSTAKA}

Alhasanah, J. U., Kertahadi, \& Riyadi. (2014). Pengaruh Kegunaan, Kualitas Informasi dan Kualitas Interaksi Layanan Web E-Commerce Terhadap Keputusan Pembelian Online ( Survei pada Konsumen www.getscoop.com). Jurnal Administrasi Bisnis (JAB), 15(2), $1-10$.

Alwafi, F., \& Magnadi, R. H. (2016). Pengaruh Persepsi Keamanan, Kemudahan, Kepercayaan Terhadap Toko dan Pengalaman Berbelanja Terhadap Minat Beli Secara Online Pada Situs Jual Beli Tokopedia.com. Diponegoro Journal Of Management, 5(2), 1-15.

Anggraeni, P., \& Madiawati, P. N. (2016). Pengaruh Kepercayaan dan Kualitas Informasi Terhadap Keputusan Pembelian Secara Online Pada Situs Www.traveloka.com. E-Proceeding Of Management, 3(2), 1-8.

Anwar, R., \& Adidarma, W. (2016). Pengaruh Kepercayaan dan Resiko Pada Minat Beli Belanja Online. Jurnal Manajemen Dan Bisnis Sriwijaya, 14(2), 155-168.

Ardyanto, D., Susilo, H., \& Riyadi. (2015). Pengaruh Kemudahan dan Kepercayaan Menggunakan E-Commerce Terhadap Keputusan Pembelian Online (Survei Pada Konsumen www.petersaysdenim.com). Jurnal Administrasi Bisnis (JAB), 22(1), 1-8.

Azwar, S. (2007). Metode Penelitian. Yogyakarta: Pustaka Belajar.

Bungin, B. (2013). Metode Penelitian Sosial dan Ekonomi. Kencana. Jakarta.

Djarwanto. (1996). Statistik Sosial Ekonomi Bagian Pertama Edisi 3. Yogyakarta: BPFEYOGYAKARTA.

Deavaj, Fan, \& Kohli. (2003). E-Loyality Elusive Ideal or Competitive Edge Communication of the ACM.46 (9), 184-191.

Djarwanto. (2001). Statistik Sosial Ekonomi Bagian Pertama Edisi 3. Yogyakarta: BPFEYOGYAKARTA.

Emzir. (2009). Metodelogi Penelitian Pendidikan, Kuantitatif dan Kualitatif. Jakarta: Raja Grafindo Persada.

Ghozali, I. (2006). Aplikasi Analisis Multivariate dengan Program SPSS. Semarang: Universitas Diponegoro.

Ghozali, I. (2009). Aplikasi Analisis Multivariate dengan Program SPSS. Cetakan ke IV. Semarang: Badan Penerbit Universitas Diponegoro.

Ghozali, I. (2011). Aplikasi Analisis Multivariate dengan Program SPSS. Semarang: Universitas Diponegoro.

Gujarati, D., N. (2007). Dasar-Dasar Ekonometrika Edisi3. Jakarta: Erlangga.

Hadi, S. (2012). Analisis Regresi. Yogyakarta: Andi Offset.

Ilham, D. A. (2017). Pengaruh Kepercayaan, Keamanan dan Kualitas Pelayanan Terhadap Keputusan Pembelian Melalui Situs Online Store Lazada Sebagai E-commerce Terpercaya Di Indonesia. Simki-Economic, 1(5), 1-12. 
Jayanti, R. D. (2015). Pengaruh Harga dan Kepercayaan Terhadap Keputusan Pembelian Secara Online (Studi Kasus Pada Harapan Maulina Hijab Jombang). Http:/lejournal. stiedewantara.ac.id, X(1), 13-27.

Jundi, M. S., \& Mudiantono. (2016). Pengaruh Kualitas Pelayanan, Citra Merek dan kepercayaan Terhadap Keputusan Pembelian dengan Nilai Yang Dipersepsikan Sebagai Mediasi. Diponegoro Journal Of Management, 5(3), 1-12.

Kotler, P. (2005). Manajemen Pemasaran, Jilid 1 dan 2. Jakarta: PT. Indeks. Kelompok Gramedia.

Kotler, P., \& Keller, K., L. (2009). Manajemen Pemasaran. Edisi 13. Jilid 1: Erlangga, Jakarta.

Kuspriyono, T. (2017). Pengaruh Kualitas Informasi Web dan Kualitas Layanan Online Terhadap Citra Bukalapak.com. Jurnal Perspektif, XV(1), 56-62.

Kuswati, Rini., \& Delima, Hafi. (2014). The Effect of Knowledge Internet Technology and Customer Trust Towards Online Shopping Intention. Reseach Methods and Organizational Studies, 148-153.

Mahkota, A. P., Suyadi, I., \& Riyadi. (2014). Pengaruh Kepercayaan dan Kenyamanan Terhadap Keputusan Pembelian Online (Studi Pada Pelanggan Website Ride Inc). Jurnal Administrasi Bisnis (JAB), 8(2), 1-7.

Nugroho, S. (2005). Perilaku Konsumen Konsep dan Implikasi untuk Strategi dan Penelitian Pemasaran. Jakarta: Kencana.

Nusarika, L. A. K., \& Purnami, N. M. (2015). Pengaruh Persepsi Harga, Kepercayaan dan Orientasi Belanja Terhadap Niat Beli Secara Online (Studi Pada Produk Fashion Online Di Kota Denpasar). E-Jurnal Manajemen Unud, 4(8), 2380-2406.

Priyantara, M. P., Indrawati, \& Djatmiko, T. (2016). Pengaruh Kualitas Sistem, Kualitas Informasi dan Kualitas Layanan Terhadap Kepuasan Konsumen (Studi Konsumen Lazada di Indonesia. E-Proceeding of Management, 3(3), 2710-2717.

Priyatno, D. (2013). Mandiri Belajar Analisis Data Dengan SPSS. Yogyakarta: Media Kom.

Raje, A., \& Vandana, T., K. (2012). Impact of E-Service Quality on Consumer Purchase Behaviour in an On-Line Shopping. IJCSMS International Journal of Computer Science and Management Studies, 12(02), 1-5.

Schiffman, Leon., \& Kanuk, L., L. (2008). Perilaku Konsumen Edisi Ketujuh. Jakarta: Indeks.

Septianita, W., Winarno, W. A., \& Arif, A. (2014). Pengaruh Kualitas Sistem, Kualitas Informasi, Kualitas Pelayanan Rail Ticketing System (RTS) Terhadap Kepuasan Pengguna (Studi Empiris Pada PT. Kereta Api Indonesia (Persero) DAOP 9 Jember). E-Journal Ekonomi Bisnis Dan Akuntansi, 1(1), 53-56.

Setiawan, E. H., \& Fauziah, A. (2017). Pengaruh Keamanan, Kemudahan, Kepercayaan, dan Risiko Kinerja Terhadap Keputusan Pembelian Seacara Online (Studi Kasus Tokopedia. com di Kabupaten Lumajang). Jurnal Ilmu Manajemen Advantage, 1(1), 64-75.

Setyarko, Y. (2016). Analisis Persepsi Harga, Promosi, Kualitas Layanan dan Kemudahan Penggunaan Terhadap Keputusan Pembelian Produk Secara Online. Jurnal Ekonomika Dan Manajemen, 5(2), 128-147.

Sugiyono. (2008). Metode Penelitian Bisnis. Bandung: Alfabeta.

Sugiyono. (2011). Metode Penelitian Bisnis. (Penelitian Kuantitatif, Kualitatif, dan R\&D. 
Bandung: C. V ALFABETA.

Sugiyono. (2013). Metode Penelitian Bisnis. (Penelitian Kuantitatif, Kualitatif, dan R\&D. Bandung: C. V ALFABETA.

Suhartanto, D. (2014). Metode Riset Pemasaran, Yogyakarta: Alfabeta.

Sujana, K. C., \& Suprapti, N. W. S. (2016). Peran Kepercayaan Dalam Memediasi Pengaruh Kualitas Situs Terhadap Niat Konsumen Untuk Berbelanja Di Situs Zalora. E-Jurnal Manajemen Unud, 5(1), 595-622.

Tsaanii, A. A. A., \& Ardini, L. (2016). Analisis Persepsi dan Keterlibatan Konsumen Terhadap Pengambilan Keputusan Pembelian dalam Transaksi E-commerce. Jurnal Ilmu Dan Riset Akuntansi, 5(6), 1-15.

Uddin, Md. R., Lopa, N. Z., \& Oheduzzaman, Md. (2014). Factors affecting customers' buying decision of mobile phone: A study on Khulna City, Bangladesh. International Journal of Managing Value and Supply Chain, 5(2), 21-28.

Wahyuni, S., Irawan, H., \& Sofyan, E. (2017). Pengaruh Kepercayaan, Kemudahan dan Kualitas Informasi Terhadap Keputusan Pembelian Online Di Situs Online Fashion Zalora.co.id. E-Proceeding of Management, 4(2), 1405-1412.

Widodo, A., Putranti, H. R. D., \& Nurchayati. (2016). Pengaruh Kualitas Sistem Aplikasi dan Kualitas Informasi Terhadap Kepuasan Pengguna Sistem Aplikasi RTS (Rail Ticketing System) Dengan Kepercayaan Sebagai Variabel Mediasi (Studi Pada Penumpang "KAI" Ekonomi Operasi 4 Semarang). Media Ekonomi Dan Manajemen, 31(2), 160-181.

Wijayanti, R. H. H., \& Harti. (2017). Pengaruh Online Consumer Reviews dan Harga Terhadap Keputusan Pembelian Produk Fashion di Toko Online Pada Generasi Muda Surabaya. Jurnal Pendidikan Tata Negara, 1(2), 49-55. 